\title{
Pemanfaatan Aplikasi OpenOffice sebagai Media Pembelajaran Siswa SMA Muhammadiyah 1 Jakarta
}

\author{
Kusdarnowo Hantoro ${ }^{1}$ \\ Universitas Bhayangkara Jakarta Raya, artawidya@gmail.com \\ Sri Rejeki ${ }^{2}$ \\ Universitas Bhayangkara Jakarta Raya, chichi_rjk@yahoo.com \\ Susi Rianti ${ }^{3}$ \\ Universitas Bhayangkara Jakarta Raya, susi.rianti@dsn.ubharajaya.ac.id \\ Tri Dharma Putra 4 \\ Universitas Bhayangkara Jakarta Raya, tridharmaputra@hotmail.com
}

\begin{abstract}
Abstrak
Komputer memerlukan perangkat lunak baik yang bersifat sumber tertutup maupun bersifat sumber terbuka. Aplikasi sumber terbuka dapat digunakan oleh siapa saja secara bebas dan dapat dikembangkan. Pelaku TI dapat memperbaiki atau meningkatkan kualitas perangkat lunaknya dengan memanfaatkan kode sumber yang dapat diperoleh dari internet. Pola sumber terbuka muncul karena kita dapat bebas berkarya, sesuai dengan keinginan profesional TI tersebut. Aktivitas pengabdian kepada masyarakat dilakukan di SMA 1 Muhammadiyah Jakarta Pusat. Metode pelaksanaan adalah penyuluhan dengan waktu efektif 2 (dua) hari, dan berlangsung pada tanggal 8 dan 9 juni 2017, berbarengan dengan acara pesantren kilat yang diadakan di sekolah tersebut. Pembelajaran ini memberikan wawasan baru bagi siswa kelas IPS tentang pemanfaatan aplikasi Open Office. Peserta sangat antusis dalam penyuluhan ini dan mengajukan banyak pertanyaan.
\end{abstract}

Kata Kunci: OpenOffice, perangkat lunak, open source

\begin{abstract}
Computer needs software, either by means of close source or open source. Open source application is the application which can be used by anyone, who can freely develop the application. Information technologi professional can enhanced and improve the quality of the software by utilizing source code from internet. Open Source pattern originating from and because of the information technology professional can develop application freely, as they want. The activity was done in Senior High School (SMA) 1 Muhammadiyah, Central Jakarta. The methode of learning is class presentation, which comprises of two days, it was conducted on 8th and 9th June 2017.This event was conducted together along with 'pesantren kilat' in this school. This learning gave insights to the social science classes of this school, about the benefits of OpenOffice application. The enthusiastic students asked many questions.
\end{abstract}

Keywords: OpenOffice, software, open source 


\section{JURNAL ABDIMAS UBJ}

\section{PENDAHULUAN}

Pada tanggal 8 - 9 Juni 2017, SMA Muhammadiyah 1 Jakarta, sedang mengadakan acara Pesantren Kilat untuk siswanya. Salah satu agenda dalam Pesantren Kilat tersebut adalah mengadakan pelatihan tentang pemanfaatan aplikasi open office sebagai media pembelajaran. Dalam rangka acara tersebutlah tim abdimas dari Universitas Bhayangkara berkolaborasi dalam mengisi acara untuk pesantren kilat. Saat itu, informasi tentang open office masih minim diketahui oleh siswa SMA Muhammadiyah 1 Jakarta. Karena itu diadakanlah pelatihan yang berjudul "Meningkatkan Kualitas Siswa SMA Muhammadiyah 1 Jakarta dengan Pemanfaatan Aplikasi Open Office sebagai Media Pembelajaran".

Diharapkan dengan adanya kegiatan pesantrean kilat ini siswa dapat memahami apa yang itu aplikasi open office. Dengan acara ini, kemampuan dan wawasan siswa tentang perangkat lunak open office meningkat. Nantinya siswa dapat meningkatkan dan mengembangkan pengetahuan sendiri dengan dasar-dasar yang telah diberikan dalam penyuluhan ini. Pengetahuan tentang sumber terbuka dan open office adalah pemahaman dasar dari teknologi informasi dan komunikasi yang dapat ditingkatkan dengan mengikuti pesantren kilat ini.

Dengan meningkatnya pengetahuan siswa terhadap aplikasi sumber terbuka dan open office, tim abdimas dari Universitas Bhayangkara merealisasikan kontribusi terhadap pengabdian masyarakat, melalui pesantren kilat yang berlangsung di SMA`1 Muhammadiyah ini. Hal ini memberikan peningkatan ilmu bagi siswa dan berarti tim abdimas Ubaharajaya berkontribusi terhadap pengembangan dan pembangunan Indonesia pada umumnya.

\section{Pengertian Perangkat Lunak Sumber Terbuka}

open office termasuk pengolah kata (writer), spreadsheet (calc), aplikasi presentasi (impress), aplikasi menggambar (draw), editor rumus (math), dan aplikasi manajemen database (base). Format file default-nya adalah Open Document Format (ODF), dan standar ISO/IEC, yang berasal dengan OpenOffice.org. Aplikasi ini juga dapat membaca berbagai format file lain dengan khususnya terutama ke format dari Microsoft Office. (OpenOffice.org, 2018)

Sebuah komputer dalam beroperasi membutuhkan perangkat lunak baik yang bersifat sumber tertutup maupun bersifat sumber terbuka. Perangkat lunak sumber terbuka merupakan aplikasi yang dapat digunakan oleh siapa saja secara bebas dan dapat dikembangkan. Pelaku TI dapat meningkatkan kualitas perangkat lunak jika ditemukan kelemahan pada perangkat lunak tersebut dengan memanfaatkan kode sumber yang tersebar di internet. Pola sumber terbuka muncul karena pelaku TI dapat bebas menulis kode pemrograman apa saja yang diinginkan. Kebebasan adalah kualitas pertama dalam hal kode sumber terbuka. Komunitas mana pun dapat bebas belajar, mengkaji ulang, mengutak-atik, dan memperbaikinya. Perlu diperhatikan bahwa sumber terbuka bersifat bebas, tetapi tidak berarti bebas sebebas-bebasnya, akan tetapi bebas disini adalah bebas untuk digunakan, dikembangkan, disebarkan dengan pertanggungjawaban secara bersama dan tanpa 


\section{JURNAL ABDIMAS UBJ}

menghilangkan hak cipta pembuatnya. Inilah penyebab perangkat lunak sumber terbuka saat ini menjadi lebih berkualitas.

\section{SMA 1 Muhammadiyah Jakarta Pusat}

SMA Muhammadiyah 1 Jakarta merupakan sebuah Sekolah Menengah Atas swasta Islam yang berada di Jakarta. Saat ini SMA Muhammadiyah di Pimpin oleh Ibu Dra. Siti Mursidah sebagai kepala sekolah dan dibantu dengan guru yang berjumlah 19 Guru. SMA Muhammadiyah memiliki Visi adalah "Terciptanya Peserta Didik Unggul Dalam Prestasi Akademik Serta Berkualitas Dalam Penguasaan Dasar Dasar IImu Pengetahuan Dan Teknologi Yang Dilandasi Iman Dan Takwa Serta Akhlakul Karimah.

Misinya adalah "Menumbuhkembangkan semangat keunggulan dan bernalar sehat kepada para peserta didik, guru dan karyawan sehingga berkemauan kuat untuk terus maju." Fasilitas yang dimiliki berupa luas tanah $3.300 \mathrm{M}^{2}$ yaitu: ruang kelas berjumlah 13 kelas, laboratorium komputer, perpustakaan, sanitasi. Siswa mendapatkan akses internet. Sumber listrik dengan daya listrik $41.500 \mathrm{Kwh}$.

SMA Muahammadiyah 1 Jakarta dalam menyelenggarakan pendidikan mempunyai 2 penjurusan yaitu IImu Pengetahuan Alam dan IImu Pengetahuan Sosial. Sedangkan dalam pembelajaran dilakukan dengan memberikan pelayanan sepenuh hati dan mengajar dengan kompetensi, sehingga dapat mengantarkan seluruh peserta didik dengan jumlah 368 siswa terdiri dari 183 siswa Laki-Iaki dan 185 siswa perempuan ke tingkat pendidikan yang lebih tinggi

\section{Lokasi Mitra}

Mitra dari kegiatan pengabdian ini adalah siswa kelas XI IPS SMA Muhammadiyah 1 Jakarta. yang beralamat di jalan Kramat Raya No. 49 Kelurahan Kramat Pulo kecamtan Senen, Jakarta Pusat.

Berikut adalah peta lokasi mitra pada Gambar 1.:

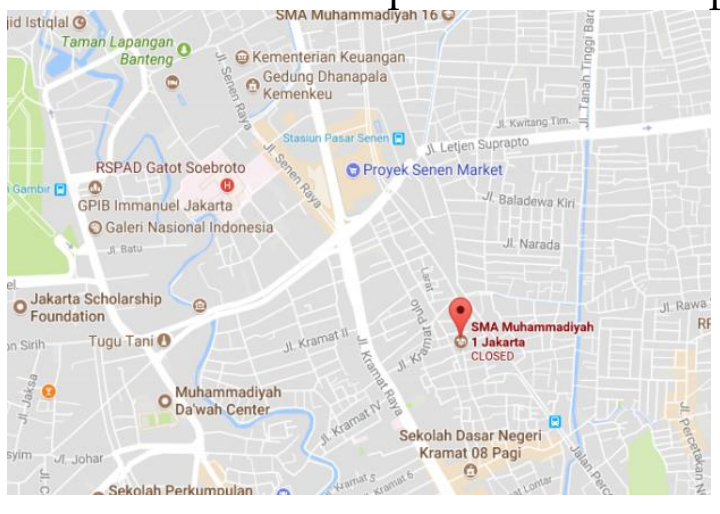

\section{Gambar 1. Peta Lokasi Mitra}

\section{METODE}

Kata media berasal dari kata medium yang berarti perantara atau pengantar. Sedangkan pembelajaran adalah proses belajar sehingga dapat diarikan bahwa media pembelajaran adalah pengantar dari proses belajar. 


\section{JURNAL ABDIMAS UBJ}

Para ahli membatasi tentang media pembelajaran. AECT mengatakan bahwa media pembelajaran adalah segala sesuatu yang digunakan orang untuk menyalurkan pesan. Media pembelajaran diatur sedemikian rupa sehingga dapat mendukung suasana belajar mengajar.

Kegiatan belajar mengajar adalah sebuah sistem. Kegiatan belajar dan mengajar terdiri dari komponen-komponen tertentu. Kurangnya satu komponen saja, dapat membuat kegiatan belajar mengajar dapat tidak berlangsung dengan sempurna.

Para ahli mendefinisikan media pembelajaran sebagai berikut:

a) Pengertian media kata "Media" berasal dari bahasa latin yang merupakan bentuk jamak dari "medium", secara harfiah berarti perantara atau pengantar. Association for Education and Communication Technology (AECT), mengartikan kata media sebagai segala bentuk dan saluran yang dipergunakan untuk proses informasi. National Education Association (NEA) mendefinisikan media sebagai segala benda yang dapat dimanipulasikan, dilihat, didengar, dibaca atau dibicarakan beserta instrumen yang dipergunakan untuk kegiatan tersebut. Sedangkan Heinich, dkk (1982) mengartikan istilah media sebagai "the term refer to anything that carries information between a source and a receiver". (Nurseto, 2011)

b) Menurut Gagne (1992), “Teori belajar, adalah cara bahwa stimulasi yang diberikan kepada individu yang sedang belajar. Masalah keduanya adalah mempertimbangkan apa yang terjadi terhadap stimulasi ini ketika stimulus mencapai individu yang belajar. Bagaimana stimulasi ini dengan cara tertentu mentransformasi kemampuan siswa dari satu keadaan ke keadaan yang lain? Pemrosesan apa yang dialami siswa hingga membuat gurunya berkesimpulan bawa dia telah belajar?. "Learning theori. These are ways, then, that stimulation is presented to the humen learner. The second part of problem to be considered concerns what happens to this stimulation when it reaches the learner. How is it transformed in such a way his capabilites from one state to another? What kind of processing does it undergo in leading his professors to conclude that he has learned?" (Gagne, 1992)

c) Teori pengolahan informasi memberikan solusi yang lebih heuristik tentang cara siswa belajar. Pengalaman sebelumnya dan hasil kognitif adalah beberapa faktor pengalaman yang mensintesa pengetahuan baru. Guru menggunakan pengetahuan ini untuk merancang metode pembelajaran yang merupakan faktor latar belakang siswa, tingkat perkembangan, kesadaran budaya, dan parameter lain yang menentukan identitas siswa. "Information processing theory provides a more heuristic solution as to how students learn. Previous experiences and cognitive outcomes are factored into the experience of synthesizing new knowledge. Instructors use knowledge of this process to design teaching methods that factor in the background of the student, developmental level, cultural awareness, and other parameters that define the student's identity." (Lineros \& Hinojosa, 2012)

Metode pembelajaran bagi siswa-siswa ini adalah sebagai berikut:

a) Presentasi kelas, anggota tim memberikan pengajaran kelas berupa pengenalan program aplikasi,

b) Praktek dengan menggunakan peragaan komputer langsung di depan kelas, bagi siswa yang membawa laptop dapat melakukan hands-on langsung di laptop masing-masing. 


\section{HASIL DAN PEMBAHASAN}

Kegiatan pengabdian pada masyarakat telah dilaksanakan di SMA Muhammadiyah 1 Jakarta oleh kelompok kami, Tim Pengabdian Dosen-dosen dari Fakultas Teknik, Universitas Bhayangkara Jakarta Raya, bersama dosen-dosen dari perguruan tinggi lainnya pada tanggal 8 - 9 Juni 2017. Adapun Judul Kegiatan Kami adalah "Meningkatkan Kualitas Siswa SMA Muhammadiyah 1 Jakarta Dengan Pemanfaatan Aplikasi OpenOffice Sebagai Media Pembelajaran ", prosesnya ada pada gambar 2.

Penjelasan dari kegiatan tersebut dapat diuraikan sebagai berikut

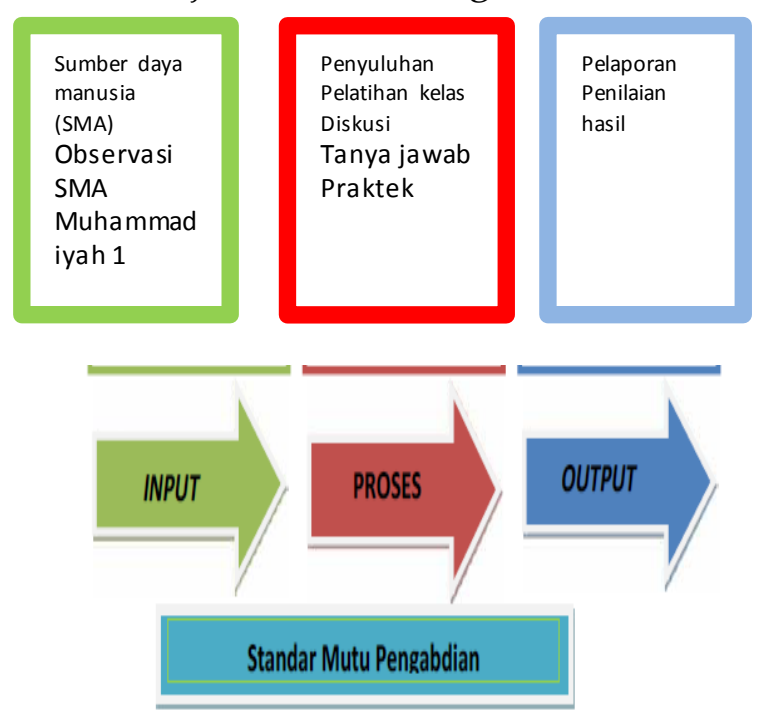

Gambar 2. Road Map kegiatan Pengabdian Masyarakat

\section{Observasi Ke SMA Muhammadiyah 1 Jakarta}

Kegiatan pengabdian masyarakat merupakan salah satu kegiatan untuk melaksanakan Tri Dharma Perguruan Tinggi yang dapat dilakukan di luar kampus. Kegiatan pengabdian masyarakat pada semester ini Kami lakukan di SMA Muhammadiyah 1 Jakarta.

Sebagai kegiatan awal, Kami melakukan observasi ke SMA Muhammadiyah 1 Jakarta, bersama teman-teman dosen dari kampus lainnya pada 10 April 2017 untuk bertemu dengan Kepala SMA Muhammadiyah 1 Jakarta, akan tetapi beliau tidak ada di tempat.

Pada tanggal 3 Mei 2017 kami bersama teman-teman dosen dari kampus lain kembali ke SMA Muhammadiyah 1 Jakarta dan bertemu dengan Kepala Sekolah, Ibu Dra. Siti Mursidah, dalam perbincangan tersebut kami mengutarakan rencana untuk melakukan kegiatan pengabdian kepada masyarakat, mendengar rencana tersebut maka Kepala Sekolah mengatakan akan membicarakan terlebih dahulu dengan guru-guru.

Pada tanggal 17 Mei 2017 kami kembali ke SMA Muhammadiyah 1 Jakarta, untuk menindaklanjuti pembicaraan yang lalu dan meminta tanggapan atas rencana kami pada SMA Muhammadiyah 1 Jakarta dan beliau mengizinkan kegiatan yang 


\section{JURNAL ABDIMAS UBJ}

akan Kami lakukan di SMA Muhammadiyah 1 Jakarta, hanya saja dimasukkan dalam satu rangkaian kegiatan sekolah yaitu: Pesantren Kilat.

Pada tanggal 24 Mei 2017 kami kembali datang ke SMA Muhammadiyah 1 Jakarta untuk berdiskusi tentang materi yang akan disampaikan pada kegiatan tersebut. Hasil diskusi bahwa peserta kegiatan pengabdian masyarakat adalah Siswa kelas X dan XI baik jurusan IPA maupun IPS, sedang XII tidak diikutkan sebagai peserta karena Kelas XII sudah lulus. Diskusi tentang materi yang akan disampaikan di tunda sampai besok.

Keesokkan harinya tepatnya tanggal 25 Mei 2017, kami berdiskusi dengan Guru dan Kepala Sekolah, setelah berbincang maka diputuskan bahwa materi yang akan diberikan oleh Tim Pengabdian Masyarakat adalah pembuatan laporan keuangan dan Matematika dengan penerapannya pada sumber terbuka. Penerapan sumber terbuka sebagai media pembelajaran saat ini sedang di galakkan oleh pemerintah khususnya pada departemen pendidikan

Untuk keberhasilan kegiatan pengabdian maka kelompok kami Tim pengabdian Masyarakat Dosen-dosen Fakultas Teknik Universitas Bhayangkara Jakarta Raya diwakili oleh Kusdarnowo Hantoro, S.Kom. M.kom. bersama teman dari kampus lainnya berkumpul di ruang Dosen Fakultas Teknik UPI YAI , untuk diskusi tentang tema kegiatan yang akan dilakukan di SMA Muhammadiyah 1 Jakarta. Hasil diskusi mendapatkan tema kegiatan adalah "Meningkatkan Kualitas Siswa SMA Muhammadiyah 1 Jakarta Dengan Pemanfaatan Aplikasi Open Source Sebagai Media Pembelajaran".

Pemilihan tema tersebut agar dapat mereduksi program studi yang ada di SMA Muhammadiyah 1 Jakarta. Dan untuk judul kegiatan diserahkan pada masingmasing kelompok disesuaikan dengan kompentensi anggota serta disesuaikan dengan mata pelajaran yang ada di lingkungan SMA Muhammadiyah 1 Jakarta.

Pada tanggal 31 Mei 2017, kami, tim pengabdian masyarakat dosen-dosen Fakultas Teknik Universitas Bhayangkara Jakarta Raya melakukan diskusi di ruang dosen Fakultas Teknik Ubhara Jaya dan hasil diskusi memutuskan bahwa ketua pelaksana kelompok Kami adalah Kusdarnowo Hantoro, SKom. Mkom, dan dengan judul kegiatan yang sesuai di atas.

Kegiatan diperuntukkan ke kelas XI IPS dan tema yang telah ditentukan adalah Meningkatkan Kualitas Siswa Muhammadiyah 1 Jakarta Dengan Pemanfaatan Aplikasi OpenOffice Sebagai Media Pembelajaran.

\section{Pelaksanaan Kegiatan}

Kegiatan pengabdian masyarakat ini merupakan kegiatan insidental yang kami lakukan bersama-sama dosen-dosen dari kampus lain dengan biaya swadana kelompok/biaya mandiri

Kegiatan pengabdian masyarakat telah kami laksanakan bersama teman dosen dari kampus lainnya di SMA Muhammadiyah 1 Jakarta pada tanggal 8 - 9 Juni 2017. Adapun rincian kegiatan sebagai berikut: 


\section{JURNAL ABDIMAS UBJ}

\section{a) Pelaksanaan hari pertama pada tanggal 8 Juni 2017}

Pada pukul 6.30 WIB tampak satu persatu dosen dari tim pengabdian masyarakat mulai berdatangan dan sesuai rencana mereka langung berkumpul di masjid sekolah yang berada di lantai 2. Setelah berkoordinasi dengan pihak sekolah pada pukul 07.00 WIB. Kepala SMA Muhammadiyah, Ibu Dra.Siti Mursidah mempersilahkan kami untuk memasuki ruang Lab Komputer sebagai tempat untuk pembukaan kegiatan. Saat kepala SMA Muhammadiyah 1 Jakarta, Ibu Dra.Siti Mursidah memberi sambutannya, beliau mengatakan bahwa saat pertama kedatangan dosen-dosen bermaksud untuk memberikan pencerahan pada peserta didik SMA Muhammadiyah 1 Jakarta merupa waktu yang sangat tepat, karena secara bersamaan SMA Muhammadiyah 1 Jakarta akan mengadakan kegiatan rutin pada bulan ramadhan berupa SANLAT (Pesantren Kilat) dan sedang mencari pengisi untuk kegiatan tersebut. Kepala sekolah menambahkan bahwa isi materi dari pesantren kilat selain untuk menambah wawasan Siswa dalam hal keagamaan akan tetapi tidak salah juga bila di isi dengan ilmu lainnya yang mendukung pembelajaran di sekolah .

Sambutan ke dua disampaikan oleh wakil dari Tim Pengabdian Masyarakat dan dilanjutkan dengan foto bersama dengan Kepala SMA Muhammadiyah 1 Jakarta, Ibu Siti Mursidah.

Selesai pembukaan, kami berdiskusi dengan pihak sekolah tentang ruang kelas yang akan Kami gunakan dan kami dipersilahkan bila ingin melihat lingkungan sekolah, hal ini karena Siswa SMA Muhammadiyah 1 Jakarta masih melakukan Sholat Dhuha bersama yang merupakan kegiatan wajib dari sekolah

Selesai berkeliling sekolah, kelompok kami, tim pengabdian nasyarakat dari Fakultas Teknik, Universitas Bhayangkara Jakarta Raya melakukan koordinasi kelompok dan sesuai rencana kelompok Kami akan memberi pencerahan pada Siswa kelas XI IPS.

Saat pukul 8.30 WIB, kami menuju kelas XI IPS untuk melaksakan kegiatan utama yaitu memberi pencerahan tentang "Pemanfaatan Aplikasi Open Source sebagai media pembelajaran". Kegiatan di kelas dimulai dengan perkenalan anggota tim pengabdian masyarakat dan dilanjutkan mempresentasikan materi yang disajikan oleh kelompok lain tentang pembuatan laporan keuangan.

Untuk mengetahui sejauh mana penerimaan Siswa dalam pencerahan yang telah disampaikan maka pembicara memberikan tugas pada siswa untuk membuat laporan kas dari suatu kasus. Saat Siswa sedang mengerjakan tugas tersebut, terdengar bunyi bel yang menandakan hari sudah menunjukkan pukul 11.30 WIB . maka kegiatan di hentikan sejenak untuk beristirahat dan sholat Dzuhur bersama di masjid sekolah.

Pada pukul 12.30 kegiatan dimulai kembali pada sesi ini kelompok kami, Dosen Fakultas Teknik Universitas Bhayangkara Jakarta Raya mempresentasikan tentang aplikasi OpenOffice mulai dari pengertiannya, kelebihan dan kelemahannya, serta contoh-contoh aplikasinya misalnya aplikasi openoffice writer, calc dan lain-lain, sedang untuk langkah-Iangkah operasional dari aplikasi tersebut di jelaskan oleh teman dari kampus lain. 


\section{JURNAL ABDIMAS UBJ}

Tepat pada jam dua siang kegiatan hari pertama diselesaikan.

\section{b) Pelaksanaan hari kedua pada tanggal 9 Juni 2017}

Pada Pukul 8.00 WIB dosen-dosen anggota tim pegabdian masyarakat mulai berdatangan satu persatu dan kedatangannya disambut oleh Kepala SMA Muhammadiyah 1 Jakarta, Ibu Dra. Siti Mursidah. Tim pengabdian masyarakat di persilahkan menunggu anggota tim pengabdian masyarakat lainnya di ruang Lab. Komputer.

Pada pukul 8.30 WIB Kepala SMA Muhammadiyah 1 Jakarta memberi pengarahan bahwa pada hari kedua ini kegiatan pengabdian masyarakat hanya sampai jam 11.30 WIB, hal ini karena Siswa wajib mengikuti sholat jumat dan dilanjutkan dengan pencerahan tentang agama sampai pukul 14.00 WIB. Selesai memberikan pengarahan, Kepala SMA Muhammadiyah 1 Jakarta mempersilahkan Tim Pengabdian Masyarakat masuk ke kelas untuk menjalankan tugasnya.

Pada pukul 9.00 WIB kegiatan dimulai dan Kelompok Kami Langsung menuju kelas XI IPS. Pada sesi ini materi yang disampaikan adalah penerapan OpenOffice Calc. Pada implementasi ini Siswa di sajikan langkah-Iangkah penggunaan OpenOffice Calc dalam pembuatan laporan keuangan, saat Pembicara menjelaskan materi tersebut, Siswa yang membawa laptop dipersilahkan untuk mengikutiny a.

Akhirnya jam sudah menunjukkan pukul sebelas lewat tigapuluh menit, maka kegiatan di hentikan dan bel berbunyi bertanda waktu kegiatan di kelas telah selesai. Siswa dan dosen pria di persilahkan untuk melakukan sholat jumat sedangkan siswi dan dosen wanita tetap di kelas untuk berfoto bersama.

\section{Jadwal Kegiatan}

Jadwal kegiatan pengabdian kepada masyarakat yang kami lakukan tersaji dalam tabel 1 berikut:

Tabel 1. Agenda Kegiatan Pengabdian Masyarakat

\begin{tabular}{|l|l|l|}
\hline Hari Pertama & Kegiatan & Pelaksana \\
\hline Waktu & $\begin{array}{l}\text { Perlengkapan Presentasi } \\
\text { Perlengkapan Absen }\end{array}$ & Tim Abdimas \\
\hline $06.30-07.00$ & $\begin{array}{l}\text { Anggota Tim Abdimas Berkumpul Di } \\
\text { Mesjid Lantai 2 }\end{array}$ & Tim Abdimas \\
\hline $07.00-08.00$ & Pembukaan & $\begin{array}{l}\text { Pihak Sekolah dan Tim } \\
\text { Abdimas }\end{array}$ \\
\hline $08.00-08.30$ & Koordinasi Ruangan & $\begin{array}{l}\text { Pihak Sekolah dan Tim } \\
\text { Abdimas }\end{array}$ \\
\hline $08.30-11.30$ & $\begin{array}{l}\text { Pembukaan kelas } \\
\text { Materi 1 } \\
\text { Pembuatan laporan keuangan }\end{array}$ & Tim Abdimas \\
\hline $12.30-14.00$ & $\begin{array}{l}\text { Materi 2 } \\
\text { OpenOffice sebagai media } \\
\text { Pembelajaran }\end{array}$ & Tim Abdimas \\
\hline Hari Kedua & \multicolumn{2}{|l}{} \\
\hline Waktu & \multicolumn{2}{|l}{} \\
\hline
\end{tabular}




\section{JURNAL ABDIMAS UBJ}

\begin{tabular}{|c|c|c|}
\hline \multirow{2}{*}{$\frac{\text { Kegiatan }}{08.00-08.30}$} & & \\
\hline & $\begin{array}{l}\text { Perlengkapan Presentasi } \\
\text { Perlengkapan Absen }\end{array}$ & $\begin{array}{l}\text { Tim Abdimas dan Pihak } \\
\text { Sekolah }\end{array}$ \\
\hline $08.30-9.00$ & Koordinasi dengan pihak sekolah & $\begin{array}{l}\text { Tim Abdimas dan Pihak } \\
\text { Sekolah }\end{array}$ \\
\hline $09.00-11.30$ & $\begin{array}{l}\text { Materi } 3 \\
\text { Open Office Writer Sebagai Media } \\
\text { Pembelajaran }\end{array}$ & Kelompok Lain \\
\hline 09:00 - 11:30 & $\begin{array}{l}\text { Materi } 4 \\
\text { Penerapan Aplikasi Calc dalam } \\
\text { pembuatan laporan keuangan }\end{array}$ & $\begin{array}{l}\text { Tim } \\
\text { Abdimas dan Tim Ubhara }\end{array}$ \\
\hline $11.30-13.00$ & Istirahat dan Sholat Jumat & \\
\hline $13.00-14.00$ & $\begin{array}{l}\text { Ramah tamah dan Foto Bersama } \\
\text { dengan Kepala SMA } \\
\text { Muhammadiyati'1 Jakarta }\end{array}$ & $\begin{array}{l}\text { Pihak Sekolah } \\
\text { Tim Abdimas }\end{array}$ \\
\hline
\end{tabular}

Adapun dokumentasi kegiatan abdimas disajikan pada gambar 3.
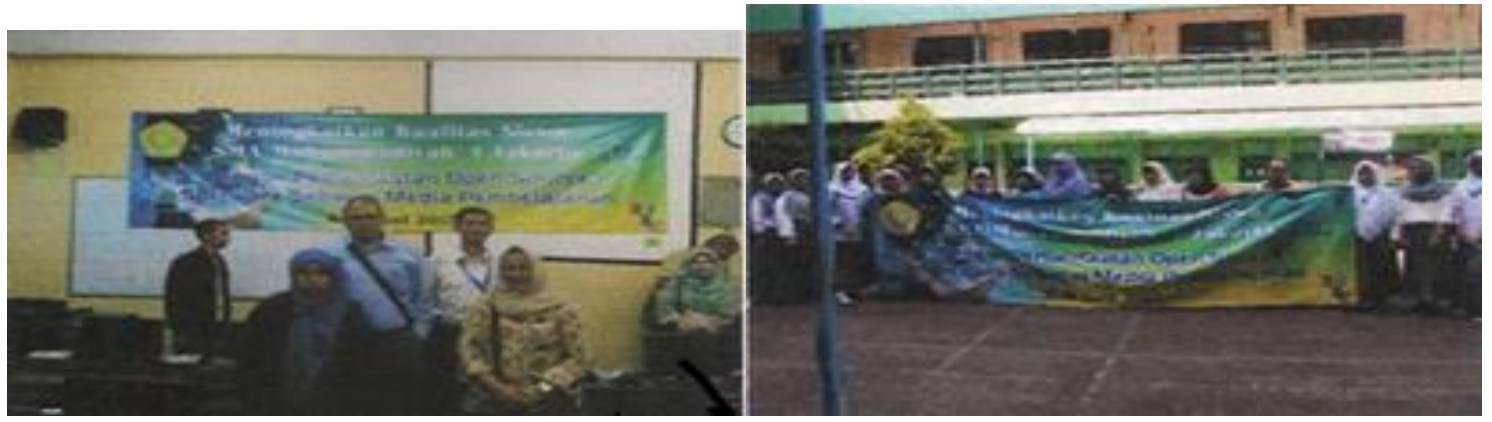

Gambar 3. Dokumentasi Kegiatan Pengabdian Kepada Masyarakat

\section{Luaran Kegiatan}

Antusiasme peserta dalam mengikuti penyuluhan terbukti dengan begitu banyak pertanyaan dari siswa selama penyuluhan berlangsung.

Berdasarkan kebutuhan yang telah diuraikan diharapkan dapat menghasilkan suatu luaran sebagai berikut:

a) Kemampuan dan wawasan siswa tentang komputer dan perangkat lunak OpenOffice makin meningkat.

b) Siswa SMA Muhammadiyah 1 Jakarta Pusat mendapatkan pengertian tentang definisi perangkat lunak sumber terbuka, serta OpenOffice.

c) Diharapkan setelah penyuluhan di pesantren kilat ini, siswa dapat meningkatkan dan mengembangkan pengetahuan sendiri dengan dasar-dasar yang telah diberikan dalam penyuluhan ini tentang sumber terbuka serta OpenOffice.

d) Siswa dapat memahami tentang teknologi informasi dan komunikasi (TIK).

e) Mengembangkan kepedulian dosen Universitas Bhayangkara Jakarta Raya (UBJ) terhadap masyarakat lingkungan disekitarnya. 


\section{JURNAL ABDIMAS UBJ}

\section{SIMPULAN DAN REKOMENDASI}

Kegiatan pengabdian pada masyarakat telah dilaksanakan di SMA Muhammadiyah 1 Jakarta oleh kelompok kami, Tim Pengabdian Dosen-dosen dari Fakultas Teknik, Universitas Bhayangkara Jakarta Raya, bersama dosen-dosen dari perguruan tinggi lainnya pada tanggal 8 - 9 Juni 2017.

Demikianlah dapat disimpulkan bahwa kegiatan pengabdian masyarakat di SMA Muhammadiyah 1 Jakarta Pusat berjalan dengan lancar. Para siswa banyak bertanya, dan mendapatkan pengetahuan baru dari penyuluhan ini.

Mungkin di tahun belajar berikutnya siswa yang dilibatkan tidak hanya siswa kelas XI saja, tetapi semua kelas, sehingga cakupan acara tersebut menjadi lebih banyak dan memberikan manfaat kepada siswa dengan lebih banyak.

\section{DAFTAR PUSTAKA}

Gagne, R. M. (1992). Learning Theori, Educational Media, and Individualized Instructions. Academy for Education Development Inc., Washington DC. Bureau of Research, 1-22.

Lineros, J. V., \& Hinojosa, M. (2012). Theories of Learning and Students Development. National Forum of Teacher Educational Journal, Volume 22 No. 3. Nurseto, T. (2011). Membuat Media Pembelajaran yang Menarik. Jurnal Ekonomi dan Pendidikan.

OpenOffice.org. (2018, March 10 February 2018). Wikipedia. Diambil kembali dari Wikipedia the Free Encyclopedia:

https://en.wikipedia.org/wiki/OpenOffice.org 


\section{JURNAL ABDIMAS UBJ}

